\title{
Seismic reduction factor evaluation and its components for steel buildings undergoing nonlinear deformations
}

\author{
Alfredo Reyes-Salazar ${ }^{1, *}$, Eden Bojórquez ${ }^{1}$, Juan Bojórquez ${ }^{1}$, \\ Federico Valenzuela-Beltran ${ }^{2}$, J. Ramon Gaxiola-Camacho ${ }^{1}$ and \\ Achintya Haldar ${ }^{3}$ \\ ${ }^{1}$ Facultad de Ingeniería, Universidad Autónoma de Sinaloa, Culiacán, Sinaloa CP 80040, México \\ ${ }^{2}$ Instituto de Ingeniería, Universidad Nacional Autónoma de México, Ciudad de México CP 04510, México \\ ${ }^{3}$ Department of Civil Engineering and Engineering Mechanics, University of Arizona, Tucson CP 85721, Arizona USA
}

\begin{abstract}
The force reduction factor $(R)$ and its components for steel buildings are evaluated in this study. The $R$ factor for single-degree-of-freedom models produces non-conservative designs. The global $R$ values can be very different than the local ones. The contribution of damping to $R$ is much more uniformly distributed and different than that of yield, implying that the latter should not be expressed in terms of viscous damping. The value of 8 specified in the codes for $R$ is justified only for low-rise buildings and global parameters, if viscous damping is considered. If damping is not considered, this value cannot be justified in any case, a value of 6 is recommended.
\end{abstract}

Keywords: Damping, ductility, force reduction factors, nonlinear deformations, steel buildings.

MosT building codes around the world permit the use of elastic procedures to determine the seismic demands on steel buildings, either for small or large deformations. Due to the relative simplicity in their application, methods like the static equivalent lateral force (SELF) procedure are broadly used. Many codes permit the use of this procedure, where the seismic forces obtained according to elastic analysis are reduced essentially using a parameter called the force (also named seismic or modification) reduction factor $(R)$. However, when this procedure is used for the case of steel buildings, it is not possible to properly capture the effects of nonlinearity introduced by large deformations and connections as well as by nonlinear geometry. In addition, dissipation of energy due to yielding of the material (or due to any other source), which have a significant effect on the structural response, is also considered in a crude manner. In fact, dissipation of energy due to nonlinear behaviour of the material is associated with one of the most important components of the $R$ factor ${ }^{1}$. Reyes-Salazar ${ }^{2}$ found that

\footnotetext{
*For correspondence. (e-mail: reyes@uas.edu.mx)
}

the $R$ parameter depends on the plastic mechanism as well as on the loading, unloading and reloading process at plastic hinges. Thus, the evaluation of the $R$ factor using sophisticated analysis procedures to capture the effects mentioned above as well as by modelling structures as realistically as possible is of central importance. It is accepted that nonlinear time-history analysis is the most accurate and reliable procedure providing realistic modelling of the structure as well as of the cyclic load deformation characteristics of its structural elements. In this study the components of the seismic reduction factor for steel buildings are numerically evaluated using nonlinear timehistory analysis and by modelling the buildings as complex three-dimensional (3D) structures; the results are compared with those given in the codes.

The use of the $R$ factor represents one of the most controversial issues in the SELF procedure. In general, it accounts, for dissipation of energy as well as for over strength; but the performance of different structural systems during past earthquakes is considered as well. However, it is not clearly stated which are the components of each of the factors involved in the mentioned reduction factors. The lack of rationality of building seismic codes related to the specified $R$ values has been pointed out in some studies ${ }^{3,4}$.

Many mechanisms contribute to the energy dissipation in actual building structures. In seismic analysis of steel buildings, this dissipation is usually considered in two ways: equivalent viscous dampers are used to model the energy dissipation at deformations within the elastic limit of buildings, while the dissipated energy due to inelastic behaviour (yielding) of the material is considered by including the inelastic relationship between resisting forces and deformations. In spite of this, it is not explicitly stated in the codes if elastic damping should be considered in the response reduction, as mentioned by Whittaker et al. ${ }^{5}$.

The main objective of this study is to calculate the seismic reduction factors for steel buildings with moment 
frames at the perimeter (PMRF). The contributions of yielding of the material, elastic-viscous damping and overstrength to the $R$ parameter are estimated. The buildings are represented by complex 3D structural models, with thousands of degrees of freedom, where the effect of dissipation of energy is explicitly considered. Other structural representations are also used and the obtained $R$ values are compared with those specified in the codes.

\section{Literature review}

Numerical studies related to the nonlinear response of different structural systems under the action of earthquakes, following different objectives, have been conducted by many researchers. The estimation of nonlinear responses of steel and concrete buildings, or any other structure modelled by single-degree-of-freedom (SDOF) systems considering the nonlinear behaviour produced by dissipation of energy has been of particular interest. Rai ${ }^{6}$ pointed out some future significant developments in earthquake-resistant design of structures within a multidisciplinary field of engineering. Kougioumtzoglou and Spanos ${ }^{7}$ proposed a method based on stochastic averaging and equivalent linearization to determine the response of lightly damped nonlinear SDOF oscillators. Sivaram et $a l^{8}{ }^{8}$ estimated strong motions at 17 stations in Southern Peninsular India using the empirical Green's function method. Some results were used to simulate ground motions, which were compared with the results of the stochastic seismological model.

The nonlinear responses of SDOF systems, in terms of the modification factor or the ductility reduction factor $\left(R_{\mu}\right)$, have been extensively studied too. Introduced first in Applied Technology Council (ATC), USA $^{9}$ at the end of the 1970s, the modification factor was used to reduce the elastic response (base shear) obtained from a 5\% damped acceleration response spectra. Several initial studies can be found in the literature ${ }^{10-13}$. Whittaker et al. ${ }^{5}$ proposed calculating $R$ as the product of factors accounting for viscous damping, ductility and overstrength. Many other methods to estimate the $R$ factor have also been proposed ${ }^{14,15}$

Most of the earlier studies were based on simplified systems, where dissipation of energy was not properly considered. It has been emphasized that dissipation of energy significantly affects the structural response ${ }^{16-18}$ and consequently the magnitude of the $R$ parameter, which also depends on the pattern of plastic hinges developed (plastic mechanism) in the structures. It is worth to mention that it is not possible to observe plastic mechanisms and to explicitly estimate the dissipate energy by modelling structures as SDOF systems.

Several studies have also been conducted concerning the evaluation of nonlinear response of different structures idealized as multi-degree-of-freedom (MDOF) models, in terms of the modification factor or the dissipated energy ${ }^{1,19-23}$. The main limitations of these studies, particularly for steel building, structures, are that sheartype structures, 2D moment frames, simplified MDOF systems or a moderate nonlinear deformation have been considered. It is worth to mention that idealizing structures by 2D frames or by simple MDOF systems, does not represent their real behaviour since the contribution of some members and some vibration modes as well as dissipation of energy are not properly considered. Moreover, moderate nonlinear deformation does not correspond to the maximum modification reduction factors. In addition, only global response parameters have been usually considered while evaluating the ductility reduction factors.

\section{Objectives}

As discussed above, the primary objective of this study is to evaluate the seismic factors $(R)$ for steel building structures with PMRF, represented by complex 3D models. The contributions to the $R$ factor of (a) dissipation of energy due to inelastic behaviour, (b) dissipation of energy due to viscous damping, and (c) overstrength, which are expressed through the ductility reduction factor $\left(R_{\mu}\right)$, the damping reduction factor $\left(R_{\zeta}\right)$, and the overstrength factor $\left(R_{\Omega}\right)$ respectively, are considered. The specific objectives are: (1) To calculate the $R_{\mu}$ parameter for steel buildings represented by complex 3D models. Equivalent 3D structural representations of steel buildings with spatial moment resisting frames (SMRF) are also included. The resulting $R_{\mu}$ factors, for global and local parameters, are compared with those of the $2 \mathrm{D}$ structural representation and those of equivalent SDOF systems. A significant level of structural deformation is considered. It is assumed that local shear panel zone or lateral torsional bucking cannot occur, in such a way that the models can reach significant plastic deformations. (2) To calculate the $R_{\zeta}$ parameter for the four structural representations mentioned above. (3) To estimate and compare the magnitude of $R$ with that specified in the codes.

\section{Procedure and mathematical formulation}

The RUAUMOKO computer program ${ }^{24}$ was used to perform the required step-by-step nonlinear seismic analyses, where the Newmark constant average acceleration method was used to numerically solve the nonlinear differential equation system that governs the problem under consideration. No strength degradation, bilinear behaviour with $5 \%$ of the initial stiffness in the second zone and concentrated plasticity were assumed in the analyses. The axial load-bending moment interaction is given by the yield interaction surface proposed by Chen and Atsuta ${ }^{25}$. 


\section{Structural models}

Due to their advantages in space and ductility capacity, moment resisting frames (MRFs) are broadly used in steel buildings. The characteristics of the structural system, however, have changed during the last three decades in some developed countries like USA. Because of the weak axis connection fragility, the common practice after the $80 \mathrm{~s}$ is to use fully restrained connections (FRC) only at the perimeter. Consequently, the redundancy significantly decreases. FRC at the interior and at the perimeter (SMRF) are commonly used in steel buildings in México, implying greater redundancy than those of systems with only PMRF. The force reduction factors of these two systems are estimated here; to this aim, equivalent models with SMRF are used.

An important issue in steel buildings with PMRF that deserves attention is that the PMRF (2D plane frames) are only considered to resist the seismic (lateral) loading, ignoring the presence of interior gravity frames (IGF). In other words, in practical seismic analysis of the structural system under consideration, it is assumed that for a given horizontal direction each PMRF resist half of the total seismic load; hence seismic analysis of this system is performed using 2D models. However, modelling the buildings as 2D models does not represent the actual behaviour since the dynamic characteristics in terms of distribution of mass and stiffness, as well as in terms of energy dissipation, may be quite different for the $2 \mathrm{D}$ and $3 \mathrm{D}$ models. Moreover, the contribution of some members and some modes is ignored. To evaluate the accuracy of this practice, the reduction factors of steel buildings modelled as $3 \mathrm{D}$ structures were compared to those calculated for $2 \mathrm{D}$ models. In addition, these results were also compared with those of the SMRF and SDOF structural representations.

SAC models: Two steel building models with 3 and 10 levels are used in this study. The models are assumed to be located in the Los Angeles area, USA and designed as part of the SAC Steel Project. The 3-level and 10-level models are denoted as SAC1 and SAC2 with fundamental lateral vibration periods of 1.02 and $2.34 \mathrm{~s}$ respectively. The elevation and plan, as well as some particular members to study response reduction at a local level, are shown in Figures 1 and 2 for the SAC1 and SAC2 models respectively. Table 1 shows the sections for beams and columns. Three per cent of critical damping is assumed. Additional information can be obtained from a FEMA report $^{26}$. In this section, the frames are modelled as complex 3D MDOF systems.

All structural members of the PMRF are assumed to be connected by FRC and are modelled as beam-column elements; the vertical members (columns) are represented by one element and the horizontal ones (girders) by two elements, having a node at the mid-span. In addition, six degrees-of-freedom per node are considered. The vertical elements of IGF are also modelled by beam-column elements and the horizontal ones by truss elements which are assumed to be connected to each other, and to the PMRF, by perfectly pinned connections (PPC). The nonlinear behaviour of all beam-column elements is as defined earlier in the text. The columns of PMRF of model SAC 1 are assumed to be fixed at the base, while those of IGF are assumed to be pinned. The slabs are modelled by near-rigid struts as considered in the FEMA study $^{26}$. The total number of degrees of freedom is 846 and 3408 for Models SAC1 and SAC2 respectively.

$E Q$ models: The design of the equivalent (EQ) 3D buildings with SMRF is performed in such a way that their dynamic properties in terms of lateral fundamental periods, mass and stiffness (lateral) are similar to those of the SAC models. Their geometry is the same as that of the SAC models (Figures 1 and 2). In order to keep the equivalence as close as possible, hypothetical sections are used. The lateral stiffness and strength of any interstory are the same for the SAC and EQ models. Moreover, the ratio of plastic moments or moments of inertia, between beams and columns of any story is essentially the same for the two systems. The same holds for exterior and interior columns. All members are assumed to be beamcolumn elements connected by FRC and the inelastic behaviour is as defined earlier in the text. These models are defined as EQ1 and EQ2 and their fundamental periods are 1.08 and $2.42 \mathrm{~s}$ respectively.

$2 D$ models: As mentioned earlier, in practical design, steel buildings with PMRF are idealized as 2D models. For a given direction, half of the seismic loading is considered to excite each PMRF constituting the plane model. These models are denoted as 2D1 and 2D2, and their lateral fundamental periods of vibration are 1.13 and $2.46 \mathrm{~s}$ respectively. The responses are calculated for the 3D and 2D models and accuracy of the above-mentioned idealization is determined.

SDOF models: Equivalent SDOF models are developed for the 3- and 10-level buildings. As for EQ models, the weight of each equivalent SDOF system equals that of its corresponding 3D SAC model, and its lateral stiffness is selected in such a way that the natural period be the same for the 3D SAC and the SDOF systems. They are denoted as models SD1 and SD2 respectively. These systems have a SDOF in each horizontal direction. Figure 3 shows the elevation and plan of these systems. In order to have the equivalence in both horizontal directions, squared hollow structural sections are used for columns. They are HSS2 $6 \times 26 \times 1 / 2$ and HSS22 $\times 22 \times 1 / 2$ for the SD 1 and SD2 models respectively. The damping ratio and yielding strength are selected to be the same for the SAC and SD models. The latter have been determined from a pushover 


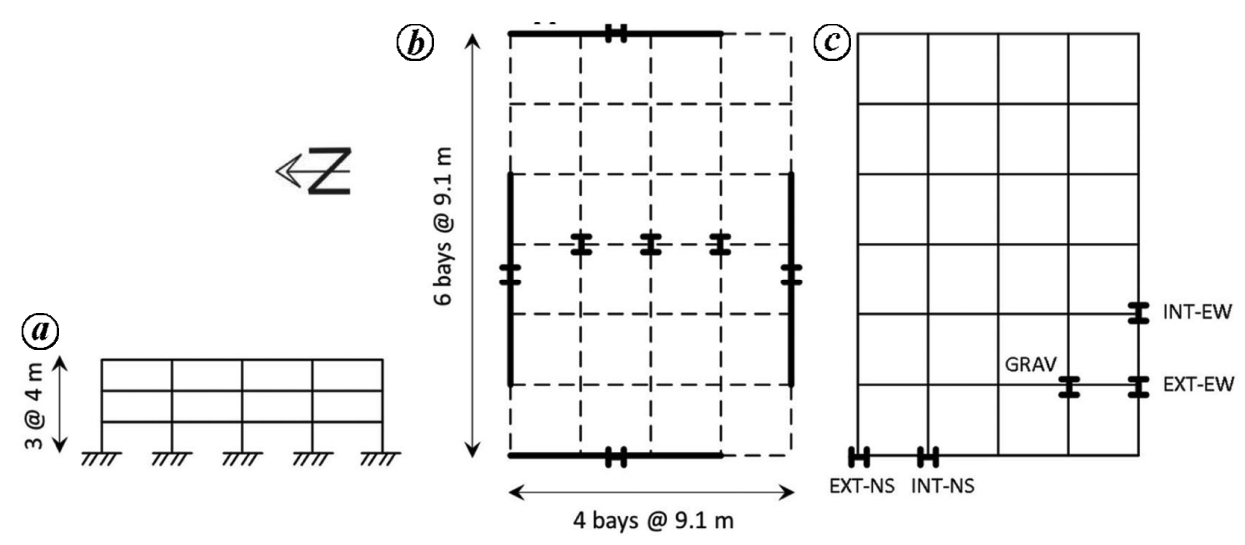

Figure 1. Plan and elevation, model SAC1. $\boldsymbol{a}$, Elevation; $\boldsymbol{b}$, Plan; $\boldsymbol{c}$, Studied elements.
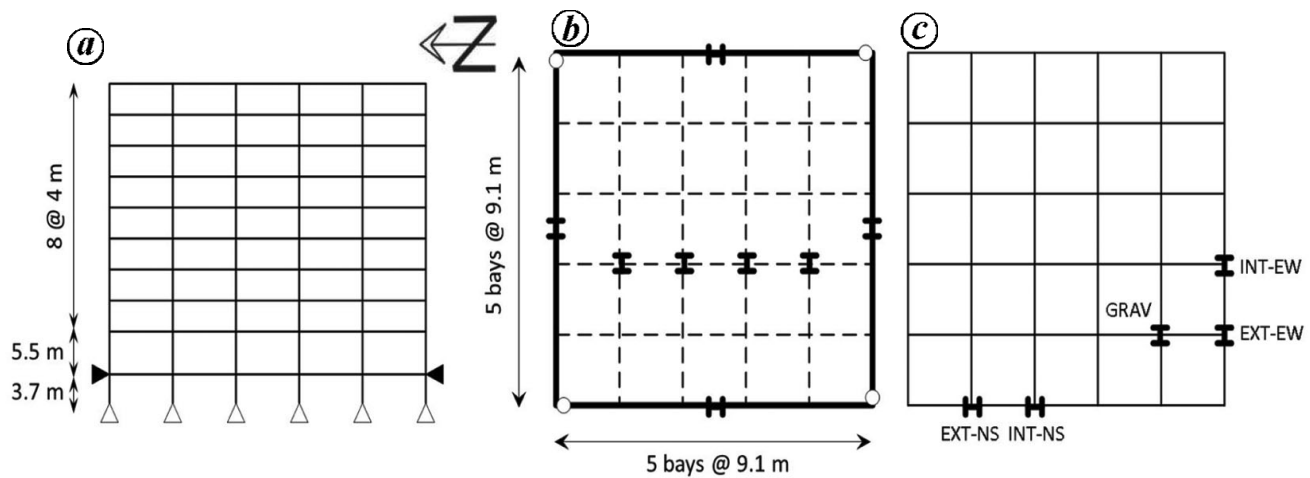

Figure 2. Plan and elevation, model SAC2. $\boldsymbol{a}$, Elevation; $\boldsymbol{b}$, Plan; $\boldsymbol{c}$, Studied elements.

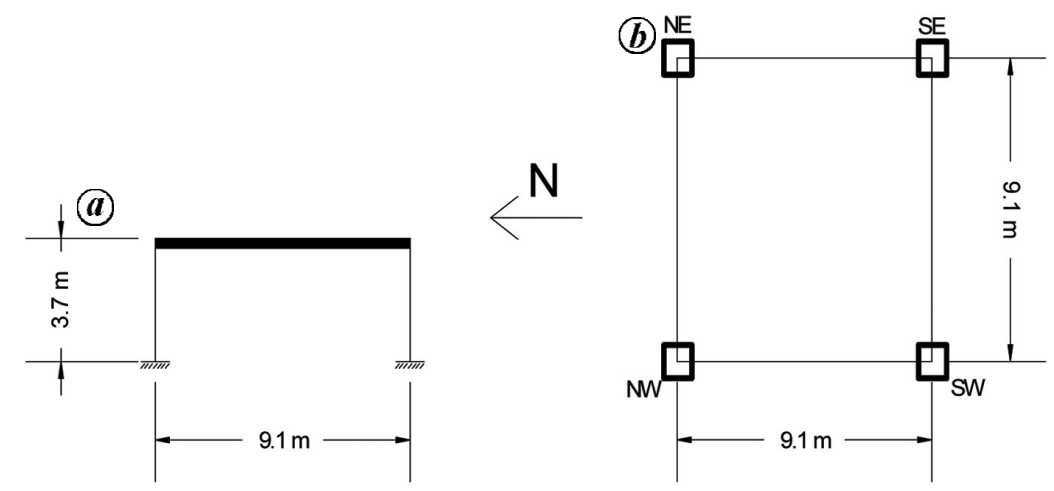

Figure 3. (a) Elevation and (b) plan of equivalent SD models.

analysis. It must be noted that in a strict sense, the SD models are not the SDOF systems studied in typical structural dynamics textbooks since axial forces can be developed in the columns under the action of horizontal excitations.

\section{Earthquake loading}

To study the issues mentioned earlier, the building models were subjected to 20 strong motions with different frequencies, recorded at the following stations:
Fun Valley, Reservoir 361; Convict Creek; Cerro Prieto; Parkfield, Joaquin Canyon; Olympia Hwy Test Lab; Utilities Bldg, Long Beach; El centro, California; Centerville Beach, Naval Facility; Gilroy Array Sta No. 4; Olympia Hwy Test Lab; Castaic-Old Ridge Route; Long Valley Dam; El Centro-Imp VallDist; Palo Alto; UCSB Goleta FF; Parkfield Fault Zone 14; Chihuahua; Canoga Park, Santa Susana; Ferndale, California; Indio, Jackson Road. Their predominant natural periods varied from 0.11 to $0.62 \mathrm{~s}$, which are defined as the periods corresponding to the largest values in the elastic pseudo-acceleration 
Table 1. Wide-flange shape sections, SAC models

\begin{tabular}{|c|c|c|c|c|c|c|c|}
\hline \multirow[b]{3}{*}{ Model } & \multirow[b]{3}{*}{ Story } & \multicolumn{3}{|c|}{ Moment-resisting frames } & \multicolumn{3}{|c|}{ Gravity frames } \\
\hline & & \multicolumn{2}{|c|}{ Columns } & \multirow[b]{2}{*}{ Girder } & \multicolumn{2}{|c|}{ Columns } & \multirow[b]{2}{*}{ Beams } \\
\hline & & Exterior & Interior & & Below penthouse & Others & \\
\hline \multirow[t]{2}{*}{1} & $1 / 2$ & $14 \times 257$ & $14 \times 311$ & $33 \times 118$ & $14 \times 82$ & $14 \times 68$ & $18 \times 35$ \\
\hline & $2 / 3$ & $14 \times 257$ & $14 \times 312$ & $30 \times 116$ & $14 \times 82$ & $14 \times 68$ & $18 \times 35$ \\
\hline \multirow[t]{9}{*}{2} & $-1 / 1$ & $14 \times 370$ & $14 \times 500$ & $36 \times 160$ & $14 \times 211$ & $14 \times 193$ & $18 \times 44$ \\
\hline & $1 / 2$ & $14 \times 370$ & $14 \times 500$ & $36 \times 160$ & $14 \times 211$ & $14 \times 193$ & $18 \times 35$ \\
\hline & $2 / 3$ & $14 \times 370$ & $14 \times 500,14 \times 455$ & $36 \times 160$ & $14 \times 211,14 \times 159$ & $14 \times 193,14 \times 145$ & $18 \times 35$ \\
\hline & $3 / 4$ & $14 \times 370$ & $14 \times 455$ & $36 \times 135$ & $14 \times 159$ & $14 \times 145$ & $18 \times 35$ \\
\hline & $4 / 5$ & $14 \times 370,14 \times 283$ & $14 \times 455,14 \times 370$ & $36 \times 135$ & $14 \times 159,14 \times 120$ & $14 \times 145,14 \times 109$ & $18 \times 35$ \\
\hline & $5 / 6$ & $14 \times 283$ & $14 \times 370$ & $36 \times 135$ & $14 \times 120$ & $14 \times 109$ & $18 \times 35$ \\
\hline & $6 / 7$ & $14 \times 283,14 \times 257$ & $14 \times 370,14 \times 283$ & $36 \times 135$ & $14 \times 120,14 \times 90$ & $14 \times 109,14 \times 82$ & $18 \times 35$ \\
\hline & $8 / 9$ & $14 \times 257,14 \times 233$ & $14 \times 283,14 \times 257$ & $27 \times 84$ & $14 \times 90,14 \times 61$ & $14 \times 82,14 \times 48$ & $18 \times 35$ \\
\hline & 9/roof & $14 \times 233$ & $14 \times 257$ & $24 \times 68$ & $14 \times 61$ & $14 \times 48$ & $16 \times 26$ \\
\hline
\end{tabular}

spectrum. The records were scaled-up to develop maximum drifts about $5 \%$ and $4 \%$ for the 3 -level and 10 -level models respectively. Additional information regarding the seismic records can be obtained from the NSMP (datasets of the National Strong Motion Project).

\section{Formulation of $R_{\mu}, R_{\zeta}$ and $R_{\Omega}$}

As stated earlier, the force reduction factor is estimated in this study by considering the effect of yielding, elastic damping and overstrength. Thus

$$
R=R_{\mu} R_{\varsigma} R_{\Omega}
$$

where $R_{\mu}, R_{\zeta}$ and $R_{\Omega}$ are the ductility reduction factor, damping reduction factor and overstrength factor respectively.

The $R_{\mu}$ factor is calculated as

$$
R_{\mu}=\frac{R_{e}(\zeta=3 \%)}{R_{i}(\zeta=3 \%)},
$$

where $R_{e}(\zeta=3 \%)$ and $R_{i}(\zeta=3 \%)$ are the peak values of a given local, or global, parameter obtained without considering (linear analysis) as well as considering (nonlinear analysis) dissipation of energy by yielding respectively. The term $(\zeta=3 \%)$ in eq. (2) indicates that $3 \%$ of critical damping is used in both types of analysis. Thus, $R_{e}$ and $R_{i}$ denote linear and nonlinear interstory shears respectively, if global parameters are being calculated, while they denote linear and nonlinear bending moments, or linear and nonlinear axial loads respectively, when local parameters are being considered. The reduction factors are $R_{\mu \mathrm{S}, \mathrm{SAC}}, R_{\mu \mathrm{S}, \mathrm{EQ}}, R_{\mu \mathrm{S}, 2 \mathrm{D}}, R_{\mu \mathrm{S}, \mathrm{SD}}$ for the $\mathrm{SAC}, \mathrm{EQ}$, $2 \mathrm{D}$ and SD models respectively, for global response parameters; the corresponding factors are $R_{\mu \mathrm{L}, \mathrm{SAC}}, R_{\mu \mathrm{L}, \mathrm{EQ}}$, $R_{\mu \mathrm{L}, 2 \mathrm{D}}, R_{\mu \mathrm{L}}$ for the case of local parameters.

The $R_{\zeta}$ parameter is calculated as

$$
R_{\zeta}=\frac{R_{e}(\zeta=0 \%)}{R_{e}(\zeta=0 \%)},
$$

where $R_{e}(\zeta=0 \%)$ and $R_{e}(\zeta=3 \%)$, similar to the case of $R_{\mu}$, represent the peak values of the parameter under consideration calculated without considering as well as considering dissipation of energy by damping respectively. The damping reduction factor is denoted as $R_{\zeta \mathrm{S}, \mathrm{SAC}}$, $R_{\zeta \mathrm{S}, \mathrm{EQ}}, R_{\zeta \mathrm{S}, 2 \mathrm{D}}$ and $R_{\zeta \mathrm{S}, \mathrm{SD}}$ for global parameters, while for local parameters it is defined by $R_{\zeta \mathrm{L}, \mathrm{SAC}}, R_{\zeta \mathrm{L}, \mathrm{EQ}}, R_{\zeta \mathrm{L}, 2 \mathrm{D}}$ and $R_{\text {¿L,SD. }}$

The values of the $R_{\Omega}$ parameter proposed in other studies for special moment resisting steel frames are adopted here ${ }^{3,27}$. The values of $R_{\Omega}$ used are 2.8 and 2.3 for the 3-level and 10-level structures respectively.

\section{Ductility reduction factor}

\section{Global ductility reduction factors}

The story (or global) ductility reduction factors for the four structural representations of the steel buildings are considered in this section. The manner in which this parameter is calculated for the $3 \mathrm{D}$ building models, namely the SAC and EQ models, needs additional discussion at this stage. For a given model, direction, interstory and strong motion, the ductility reduction factors for interstory shears are calculated and averaged over all the frames (PMRF and IGF) that conform the 3D buildings for the interstory under consideration. The average is denoted as $R_{\mu \mathrm{S}, \mathrm{SAC}}, R_{\mu \mathrm{S}, \mathrm{EQ}}$, for the SAC and EQ models 
respectively. It is accepted that the ductility reduction factors should be associated to a deformation state close to the formation of a collapse mechanism ${ }^{3,5,28}$. Since the pattern of plastic hinges developed in the models for some strong motions is close to defining a collapse mechanism for maximum drifts of $5 \%$ and $4 \%$ for the 3-level and 10-level models respectively, here we consider that the maximum deformation capacity occurs for these drift values. Then the maximum reduction factors are assumed to occur for these levels of deformations.

Plots for $R_{\mu \mathrm{S}, \mathrm{SAC}}, R_{\mu \mathrm{S}, \mathrm{EQ}}, R_{\mu \mathrm{S}, 2 \mathrm{D}}$ and $R_{\mu \mathrm{S}, \mathrm{SD}}$ were developed for each strong motion, for each story of both models and horizontal directions. In total, 16 plots were developed; however, they are not presented here due to lack of space. Nevertheless, it is worth to mention that $R_{\mu \mathrm{s}}$ values, for any of the structural representation, significantly varies from one seismic motion to another without showing any tendency, though the level of deformation is similar for each seismic record. It reflects a considerable effect of frequency contents of the seismic records on structural response. It was also observed that the reduction of interstory shears may significantly change from one story to another, particularly for the $3 \mathrm{D}$ representations.

In order to compare the $R_{\mu \mathrm{s}}$ values (and the associated values of $R$, discussed later in the text) obtained in this study with those specified in the codes, the $R_{\mu \mathrm{s}}$ values for each structural representation were averaged over all the stories (as usually made for story ductility demands); the results are denoted by $R_{\mu \mathrm{G}}$. Plots for this parameter were also developed, but are not presented either. The results are given only in terms of the fundamental statistics, namely the mean value (MV) and the coefficient of variation (COV) (Table 2). Results indicate that for the 3-level model, MVs of $R_{\mu \mathrm{G}, \mathrm{EQ}}(1.86$ and 1.79) are, in general, larger than those of $R_{\mu \mathrm{G}, \mathrm{SAC}}(1.73$ and 1.59) which in turn are larger than those of $R_{\mu \mathrm{G}, 2 \mathrm{D}}(1.51$ and 1.53). Whereas for the 10-level model, the MVs of $R_{\mu \mathrm{G}, \mathrm{SAC}}$ are quite similar to that of $R_{\mu \mathrm{G}, \mathrm{EQ}}$ (about 1.30) which in turn are significantly smaller than those of $R_{\mu \mathrm{G}, 2 \mathrm{D}}$ (about 2.0). This implies that the magnitude of the ductility reduction factors is considerably influenced by the structural complexity. In all cases, the MVs are much larger for the SD models (ranging from 2.68 to 2.98). One of the reasons for this is that, although there is equivalence between the SD and MDOF models in terms of weight, strength and stiffness, the dissipated energy and the number of incursions in the inelastic range are significantly larger for the SD models. In addition, when yielding occurs in the SD models, plastic hinges are simultaneously developed at both ends of all structural elements (eight columns) implying a totally plasticized structure, whereas for the SAC and EQ models (which have hundreds of beam and columns), even if significant yielding occurs, plastic hinges are developed only in a relatively small number of structural members. Thus, the dissipation of energy is overestimated when SD systems are used, resulting in large unrealistic ductility reduction factors and consequently in non-conservative designs. It is also observed that for a given model, MV and COV are similar for the EW and NS directions and that $\mathrm{COV}$ is moderate for the MDOF structural representations (SAC, EQ and 2D), but it is significant for the SD models.

\section{Local ductility reduction factors}

The $R_{\mu \mathrm{L}}$ values for bending moments and axial loads at some base columns (Figure $1 c$ and $2 b$ ), are discussed now. Graphs for individual strong motions, similar to those of $R_{\mu \mathrm{s}}$, are developed for the two horizontal directions of the two steel buildings under consideration. However, only MV and COV are given (Table 3). It is shown that the MVs of $R_{\mu \mathrm{L}}$ may significantly change from one building to another, from one structural representation to another, from one column location to another, and from one local response parameter to another. For bending moments of both buildings, MVs of $R_{\mu \mathrm{L}}$ are greater for the SD models, values of up to 2.65 are observed; followed by those of the $2 \mathrm{D}$, EQ and SAC models. In fact, for these three structural representations of the 10-level building, the MVs are only slightly larger than unity. For the case of axial loads and the 3-level building, however, excepting the EXT-EW column, the $\mathrm{MVs}$ are larger for the SAC and EQ models (maximum values are about 1.60), followed by those of the SD and 2D models. For the case of the 10-level building, the MVs are slightly greater than unity in all cases, being larger for the SD models followed by those of the 2D, SAC and EQ models.

It is also noted that the MVs of $R_{\mu \mathrm{L}}$ are greater for bending moments than for axial loads for the SD and 2D models; however, the values are larger for axial load for the SAC and EQ models. In general, the local reduction factors (and their estimation uncertainty) are larger for the 3-level than for the 10-level models. This variation indicates again, as stated earlier for $R_{\mu \mathrm{G}}$, an important effect of the structural complexity and structural representation on the magnitude of the $R_{\mu \mathrm{L}}$ parameter. By comparing the results of Tables 2 and 3 , it can be seen that the MVs may be significantly larger for $R_{\mu \mathrm{G}}$, when compared to those of $R_{\mu \mathrm{L}}$, particularly for the 10-level building.

\section{Damping reduction factor}

The damping reduction factor, calculated according to eq. (3), is discussed now. As for $R_{\mu \mathrm{S}}$ of the $3 \mathrm{D}$ structural representations, the global damping reduction factors were averaged over all frames (PMRF and IGF); the results are represented by the $R_{\zeta \mathrm{S}}$ parameter. Plots for individual strong motions and stories were also developed 
Table 2. Mean value (MV) and coefficient of variation $(\mathrm{COV})$ for $R_{\mu \mathrm{G}}$ and $R_{\zeta \mathrm{G}}$

\begin{tabular}{|c|c|c|c|c|c|c|}
\hline \multirow[b]{3}{*}{ Parameter } & \multirow{3}{*}{$\begin{array}{c}\text { Structural } \\
\text { representation }\end{array}$} & \multirow[b]{3}{*}{ Statistics } & \multicolumn{4}{|c|}{ Model } \\
\hline & & & \multicolumn{2}{|c|}{3 Levels } & \multicolumn{2}{|c|}{10 Levels } \\
\hline & & & NS & EW & NS & EW \\
\hline \multirow{8}{*}{$R_{\mu \mathrm{G}}$} & SAC & MV & 1.73 & 1.59 & 1.34 & 1.30 \\
\hline & & $\mathrm{COV}$ & 0.21 & 0.22 & 0.15 & 0.13 \\
\hline & EQ & MV & 1.86 & 1.79 & 1.34 & 1.27 \\
\hline & & $\mathrm{COV}$ & 0.19 & 0.21 & 0.20 & 0.19 \\
\hline & $2 \mathrm{D}$ & MV & 1.51 & 1.53 & 1.95 & 2.01 \\
\hline & & $\mathrm{COV}$ & 0.18 & 0.16 & 0.24 & 0.23 \\
\hline & SD & MV & 2.68 & 2.98 & 2.76 & 2.86 \\
\hline & & $\mathrm{COV}$ & 0.41 & 0.35 & 0.36 & 0.35 \\
\hline \multirow[t]{8}{*}{$R_{\zeta \mathrm{G}}$} & SAC & MV & 1.92 & 1.86 & 1.79 & 1.84 \\
\hline & & $\mathrm{COV}$ & 0.23 & 0.19 & 0.15 & 0.15 \\
\hline & EQ & MV & 1.76 & 1.87 & 1.77 & 1.75 \\
\hline & & $\mathrm{COV}$ & 0.16 & 0.20 & 0.20 & 0.17 \\
\hline & $2 \mathrm{D}$ & MV & 2.01 & 1.83 & 1.84 & 1.82 \\
\hline & & $\mathrm{COV}$ & 0.24 & 0.18 & 0.16 & 0.16 \\
\hline & SD & MV & 1.84 & 1.83 & 1.59 & 1.70 \\
\hline & & $\mathrm{COV}$ & 0.22 & 0.25 & 0.13 & 0.21 \\
\hline
\end{tabular}

Table 3. $\mathrm{MV}$ and $\mathrm{COV}$ for $R_{\mu \mathrm{L}}$

\begin{tabular}{|c|c|c|c|c|c|c|c|c|c|c|c|c|c|c|c|c|c|}
\hline \multirow{2}{*}{$\begin{array}{l}\text { Model } \\
\text { (1) }\end{array}$} & \multirow{2}{*}{$\begin{array}{l}\text { Column location } \\
\text { (2) }\end{array}$} & \multicolumn{4}{|c|}{$R_{\mu \mathrm{L}, \mathrm{SAC}}$} & \multicolumn{4}{|c|}{$R_{\mu \mathrm{L}, \mathrm{EQ}}$} & \multicolumn{4}{|c|}{$R_{\mu \mathrm{L}, 2 \mathrm{D}}$} & \multicolumn{4}{|c|}{$R_{\mu \mathrm{L}, \mathrm{SD}}$} \\
\hline & & \multicolumn{2}{|c|}{ Axial } & \multicolumn{2}{|c|}{ Moment } & \multicolumn{2}{|c|}{ Axial } & \multicolumn{2}{|c|}{ Moment } & \multicolumn{2}{|c|}{ Axial } & \multicolumn{2}{|c|}{ Moment } & \multicolumn{2}{|c|}{ Axial } & \multicolumn{2}{|c|}{ Moment } \\
\hline \multirow{4}{*}{3 Levels } & EXT-NS or NW & 1.64 & 0.27 & 1.00 & 0.01 & 1.58 & 0.28 & 1.03 & 0.08 & 1.22 & 0.17 & 1.52 & 0.19 & 1.18 & 0.29 & 2.55 & 0.25 \\
\hline & INT-NS or NE & 1.48 & 0.34 & 0.95 & 0.35 & 1.53 & 0.37 & 0.92 & 0.29 & 1.00 & 0.01 & 1.53 & 0.18 & 1.17 & 0.27 & 2.57 & 0.24 \\
\hline & EXT-EW or SW & 0.96 & 0.14 & 0.98 & 0.12 & 0.95 & 0.15 & 1.07 & 0.26 & 1.17 & 0.15 & 1.56 & 0.19 & 1.17 & 0.37 & 2.63 & 0.28 \\
\hline & INT-EW or SE & 1.44 & 0.32 & 1.53 & 0.23 & 1.44 & 0.32 & 1.57 & 0.24 & 1.01 & 0.02 & 1.59 & 0.18 & 1.16 & 0.37 & 2.65 & 0.26 \\
\hline Average & & \multicolumn{2}{|c|}{1.38} & \multicolumn{2}{|c|}{1.12} & \multicolumn{2}{|c|}{1.38} & \multicolumn{2}{|c|}{1.15} & \multicolumn{2}{|c|}{1.10} & \multicolumn{2}{|c|}{1.55} & \multicolumn{2}{|c|}{1.17} & \multicolumn{2}{|c|}{2.60} \\
\hline \multirow[t]{4}{*}{10 Levels } & EXT-NS or NW & 1.10 & 0.03 & 1.07 & 0.07 & 1.11 & 0.01 & 1.07 & 0.10 & 1.09 & 0.03 & 1.17 & 0.08 & 1.17 & 0.07 & 2.10 & 0.25 \\
\hline & INT-NS or NE & 1.11 & 0.04 & 1.08 & 0.06 & 1.11 & 0.03 & 1.07 & 0.09 & 1.10 & 0.02 & 1.18 & 0.08 & 1.17 & 0.08 & 2.10 & 0.24 \\
\hline & EXT-EW or SW & 1.10 & 0.02 & 1.07 & 0.07 & 1.09 & 0.01 & 1.08 & 0.07 & 1.09 & 0.03 & 1.18 & 0.07 & 1.10 & 0.07 & 2.05 & 0.22 \\
\hline & INT-EW or SE & 1.09 & 0.01 & 1.06 & 0.07 & 1.09 & 0.02 & 1.08 & 0.09 & 1.10 & 0.01 & 1.18 & 0.08 & 1.10 & 0.06 & 2.05 & 0.24 \\
\hline
\end{tabular}

for $R_{\zeta \mathrm{S}, \mathrm{SAC}}, R_{\zeta \mathrm{S}, \mathrm{EQ}}, R_{\zeta \mathrm{S}, 2 \mathrm{D}}$ and $R_{\zeta \mathrm{S}, \mathrm{SD}}$, but they are not shown here. However, it is worth to mention that the variability of $R_{\zeta \mathrm{S}}$ from one story to another is much smaller than that of $R_{\mu \mathrm{s}}$, implying a more uniform distribution of response reduction through the height of the structure.

As stated earlier for the $R_{\mu \mathrm{s}}$ parameter, in order to have a damping reduction factor comparable with the $R$ parameter specified in the codes, the $R_{\zeta \mathrm{S}}$ values are averaged over the stories and the results are defined by $R_{\zeta \mathrm{G}}$ (Table 2 ). By comparing the MVs of $R_{\mu \mathrm{G}}$ with those of $R_{\zeta \mathrm{G}}$ given in Table 2, it is observed that unlike the case of $R_{\mu \mathrm{G}}$, the MVs of $R_{\zeta \mathrm{G}}$ are not always larger for the SD models. In fact, they are similar for the four structural representations. This implies that yielding and damping are similar in one sense, but different in another: both of them reduce the seismic response, but the reduction produced by damping is more uniform through the different structural representations and, as stated earlier, through the height of the buildings. It is also observed that the MVs of $R_{\zeta \mathrm{G}}$ are greater than those of $R_{\mu \mathrm{G}}$ for the SAC, EQ and 2D models in most of the cases; however, for the SD models, the MVs may be significantly larger for the $R_{\mu \mathrm{G}}$ parameter. These results clearly indicate again that the influence of yielding on the seismic response reduction should not be expressed in terms of an amount of equivalent viscous damping.

Results for local damping reduction factors are presented next. Plots for $R_{\zeta L}$ for the case of individual strong motions are developed, but only the statistics is 
RESEARCH ARTICLES

Table 4. $\mathrm{MV}$ and $\mathrm{COV}$ for $R_{\S \mathrm{L}}$

\begin{tabular}{|c|c|c|c|c|c|c|c|c|c|c|c|c|c|c|c|c|c|}
\hline \multirow{2}{*}{$\begin{array}{l}\text { Model } \\
\text { (1) }\end{array}$} & \multirow{2}{*}{$\begin{array}{l}\text { Column location } \\
\text { (2) }\end{array}$} & \multicolumn{4}{|c|}{$R_{\S \mathrm{L}, \mathrm{SAC}}$} & \multicolumn{4}{|c|}{$R_{\text {ऽL,EQ }}$} & \multicolumn{4}{|c|}{$R_{\zeta \mathrm{L}, 2 \mathrm{D}}$} & \multicolumn{4}{|c|}{$R_{\zeta \mathrm{L}, \mathrm{SD}}$} \\
\hline & & \multicolumn{2}{|c|}{ Axial } & \multicolumn{2}{|c|}{ Moment } & \multicolumn{2}{|c|}{ Axial } & \multicolumn{2}{|c|}{ Moment } & \multicolumn{2}{|c|}{ Axial } & \multicolumn{2}{|c|}{ Moment } & \multicolumn{2}{|c|}{ Axial } & \multicolumn{2}{|c|}{ Moment } \\
\hline \multirow[t]{4}{*}{3 Levels } & EXT-NS or NW & 2.35 & 0.28 & 1.92 & 0.25 & 3.47 & 0.39 & 1.92 & 0.24 & 3.44 & 0.33 & 2.06 & 0.26 & 3.68 & 0.44 & 1.84 & 0.21 \\
\hline & INT-NS or NE & 3.78 & 0.41 & 1.91 & 0.25 & 3.63 & 0.37 & 1.91 & 0.25 & 3.59 & 0.30 & 1.96 & 0.27 & 3.72 & 0.43 & 1.85 & 0.23 \\
\hline & EXT-EW or SW & 2.31 & 0.25 & 2.04 & 0.23 & 3.29 & 0.42 & 2.03 & 0.24 & 3.20 & 0.33 & 2.07 & 0.26 & 3.26 & 0.44 & 1.84 & 0.22 \\
\hline & INT-EW or SE & 3.81 & 0.43 & 2.04 & 0.22 & 3.38 & 0.45 & 2.04 & 0.22 & 4.17 & 0.31 & 2.06 & 0.26 & 3.58 & 0.48 & 1.86 & 0.23 \\
\hline Average & & \multicolumn{2}{|c|}{3.06} & \multicolumn{2}{|c|}{1.98} & \multicolumn{2}{|c|}{3.44} & \multicolumn{2}{|c|}{1.98} & \multicolumn{2}{|c|}{3.60} & \multicolumn{2}{|c|}{2.04} & \multicolumn{2}{|c|}{3.56} & \multicolumn{2}{|c|}{1.85} \\
\hline \multirow[t]{4}{*}{10 Levels } & EXT-NS or NW & 3.03 & 0.33 & 1.76 & 0.15 & 2.19 & 0.33 & 1.76 & 0.15 & 3.79 & 0.47 & 1.82 & 0.18 & 2.59 & 0.34 & 2.48 & 0.33 \\
\hline & INT-NS or NE & 2.37 & 0.30 & 1.76 & 0.15 & 2.77 & 0.34 & 1.72 & 0.13 & 1.86 & 0.15 & 1.78 & 0.15 & 3.15 & 0.36 & 2.88 & 0.38 \\
\hline & EXT-EW or SW & 3.05 & 0.33 & 1.79 & 0.14 & 3.18 & 0.33 & 1.79 & 0.15 & 2.02 & 0.21 & 1.80 & 0.17 & 1.68 & 0.15 & 1.59 & 0.12 \\
\hline & INT-EW or SE & 2.73 & 0.27 & 1.76 & 0.15 & 2.61 & 0.31 & 1.78 & 0.17 & 3.45 & 0.43 & 1.81 & 0.18 & 1.72 & 0.17 & 1.58 & 0.13 \\
\hline
\end{tabular}

given (Table 4). It is shown that the variations from one building to another, from one structural representation to another, from one column location to another, and from one response parameter to another, are much smaller than those of $R_{\mu \mathrm{L}}$ (a similar conclusion was made earlier when $R_{\mu \mathrm{G}}$ and $R_{\zeta \mathrm{G}}$ were compared). For axial loads and the 3level model, the MVs of $R_{\zeta \mathrm{L}}$ are similar for the 2D and SD models (ranging from 3.20 to 4.17), followed by those of the EQ and SAC models (ranging from 2.31 to 3.81); while for bending moments they are similar for the MDOF representations (ranging from 1.91 to 2.07), which in turn are a slightly greater than those of the SD representation (about 1.84). For axial loads and the 10level building, the maximum MVs occur for the 2D structural representation (ranging from 1.86 to 3.79 ) followed by those of the SAC, EQ and SD models, while for bending moments, as for the 3-level model, the MVs of $R_{\zeta \mathrm{L}}$ are similar for the MDOF models, but in this case the largest values occur for the SD models (2.88).

Results also indicate that, unlike the case of $R_{\mu \mathrm{L}}$ (Table 3 ), the $R_{\zeta \mathrm{L}} \mathrm{MV}$ and $\mathrm{COV}$ are larger for axial loads than for bending moments, essentially for all the structural representations, and that, unlike the results of the comparison between $R_{\mu \mathrm{G}}$ and $R_{\mu \mathrm{L}}$ (Tables 2 and 3), the MVs of $R_{\zeta}$ are larger for local $\left(R_{\zeta \mathrm{L}}\right)$ than for global response parameters $\left(R_{\zeta \mathrm{G}}\right)$. It is also observed from Table 4 that the axial load mean values of $R_{\zeta \mathrm{L}}$ and the uncertainty in their estimation are, in most of the cases, larger for interior than for exterior columns, while for the case of moments they are similar for both types of columns.

\section{Force reduction factor}

The global $\left(R_{\mathrm{G}}\right)$ and local force reduction factors $\left(R_{\mathrm{L}}\right)$, calculated according to eq. (1), are discussed now. The values of 2.8 and 2.3 for $R_{\Omega}$ mentioned earlier are used and they are assumed to be the same for $R_{\mathrm{G}}$ and $R_{\mathrm{L}}$, as well as for the four structural representations under consideration. The fundamental statistics of $R_{\mathrm{G}}$ is summarized in Table $5\left(R_{\mu} R_{\zeta} R_{\Omega}\right)$. It is shown that the MVs of $R_{\mathrm{G}}$ (and the uncertainty in their estimation) are very large for the SD models (ranging from 10.05 to 15.94 ); since $R_{\mu \mathrm{G}}$ is a component of $R_{\mathrm{G}}$, the unrealistic large values obtained for the former, due to an overestimation of the dissipated energy, are obviously reflected in the latter. For the MDOF structural representations (SAC, EQ and 2D) of the 3-level building, the MVs are quite similar for the SAC and EQ models (ranging from 8.21 to 9.31), which in turn are larger than those of the 2D model (ranging from 7.85 to 8.33); while for the MDOF models of the 10-level building, they are larger for the $2 \mathrm{D}$ model (ranging from 8.06 to 8.30), followed by those of the EQ and SAC models. The MVs of $R_{\mathrm{G}}$ are in all cases greater for the 3-level than for the 10-level models, indicating as stated earlier, that the effect of the structural model complexity on the magnitude of the $R_{\mathrm{G}}$ factor is considerable.

Table 6 presents results for the $R_{\mathrm{L}}$ parameter. A significant variation is observed from one structural representation to another, from one building to another, from one response parameter to another and from one column location to another. Values as small as 4.20 (bending moments, 10-level building, INT-NS column, 2D model) and as large as 13.79 (bending moment, 3-level building, SE column, SD model) are observed. As for the $R_{\mathrm{G}}$ factor, the largest values occur for the SD models and, as for $R_{\mathrm{G}}, R_{\mathrm{L}}$ is much greater for the 3-level building than for the 10-level building. With the exception of the SD models, the MVs of $R_{\mathrm{L}}$ are larger for axial loads than for bending moments. By comparing the averaged $R_{\mathrm{L}}$ values over all the column elements of Table 6 with those of $R_{\mathrm{G}}$ (Table 5), it is observed that for axial loads of the 3-level buildings, excepting the results of the SD models, the $R_{\mathrm{L}}$ MVs are greater than those of $R_{\mathrm{G}}$; for the 10-level model, the MVs of $R_{\mathrm{L}}$ are greater than those of $R_{\mathrm{G}}$ for the four structural representations. For bending moments, the 
Table 5. $\mathrm{MV}$ and $\mathrm{COV}$ for $R_{\mathrm{G}}$

\begin{tabular}{|c|c|c|c|c|c|c|}
\hline \multirow[b]{3}{*}{$R_{\mathrm{G}}$} & \multirow{3}{*}{$\begin{array}{c}\text { Structural } \\
\text { representation }\end{array}$} & \multirow[b]{3}{*}{ Statistics } & \multicolumn{4}{|c|}{ Model } \\
\hline & & & \multicolumn{2}{|c|}{3 Levels } & \multicolumn{2}{|c|}{10 Levels } \\
\hline & & & NS & EW & NS & EW \\
\hline \multirow[t]{8}{*}{$R_{\mu} R_{\zeta} R_{\Omega}$} & SAC & MV & 9.31 & 8.21 & 5.48 & 5.50 \\
\hline & & $\mathrm{COV}$ & 0.31 & 0.27 & 0.19 & 0.19 \\
\hline & EQ & MV & 9.04 & 9.27 & 5.43 & 5.08 \\
\hline & & $\mathrm{COV}$ & 0.21 & 0.26 & 0.26 & 0.25 \\
\hline & $2 \mathrm{D}$ & MV & 8.33 & 7.85 & 8.06 & 8.30 \\
\hline & & $\mathrm{COV}$ & 0.21 & 0.24 & 0.20 & 0.24 \\
\hline & SD & MV & 13.95 & 15.44 & 10.05 & 11.23 \\
\hline & & $\mathrm{COV}$ & 0.54 & 0.46 & 0.36 & 0.42 \\
\hline \multirow[t]{8}{*}{$R_{\mu} R_{\Omega}$} & SAC & MV & 4.84 & 4.45 & 3.08 & 2.99 \\
\hline & & $\mathrm{COV}$ & 0.31 & 0.27 & 0.19 & 0.19 \\
\hline & EQ & MV & 5.21 & 5.01 & 3.08 & 2.92 \\
\hline & & $\mathrm{COV}$ & 0.21 & 0.26 & 0.26 & 0.25 \\
\hline & $2 \mathrm{D}$ & MV & 4.23 & 4.28 & 4.49 & 4.62 \\
\hline & & $\mathrm{COV}$ & 0.21 & 0.24 & 0.20 & 0.24 \\
\hline & SD & MV & 7.52 & 8.35 & 6.35 & 6.58 \\
\hline & & $\mathrm{COV}$ & 0.54 & 0.46 & 0.36 & 0.42 \\
\hline
\end{tabular}

Table 6. $\mathrm{MV}$ and COV for $R_{\mathrm{L}}$

\begin{tabular}{|c|c|c|c|c|c|c|c|c|c|c|c|c|c|c|c|c|c|}
\hline \multirow{2}{*}{$\begin{array}{l}\text { Model } \\
\text { (1) }\end{array}$} & \multirow{2}{*}{$\begin{array}{l}\text { Column location } \\
\text { (2) }\end{array}$} & \multicolumn{4}{|c|}{$R_{\mathrm{L}, \mathrm{SAC}}$} & \multicolumn{4}{|c|}{$R_{\mathrm{L}, \mathrm{EQ}}$} & \multicolumn{4}{|c|}{$R_{\mathrm{L}, 2 \mathrm{D}}$} & \multicolumn{4}{|c|}{$R_{\mathrm{L}, \mathrm{SD}}$} \\
\hline & & \multicolumn{2}{|c|}{ Axial } & \multicolumn{2}{|c|}{ Moment } & \multicolumn{2}{|c|}{ Axial } & \multicolumn{2}{|c|}{ Moment } & \multicolumn{2}{|c|}{ Axial } & \multicolumn{2}{|c|}{ Moment } & \multicolumn{2}{|c|}{ Axial } & \multicolumn{2}{|c|}{ Moment } \\
\hline \multirow[t]{4}{*}{3 Levels } & EXT-NS or NW & 10.57 & 0.34 & 5.39 & 0.24 & 15.69 & 0.39 & 5.47 & 0.23 & 12.34 & 0.37 & 8.20 & 0.25 & 12.83 & 0.71 & 13.46 & 0.40 \\
\hline & INT-NS or NE & 14.84 & 0.42 & 4.97 & 0.31 & 14.04 & 0.42 & 4.85 & 0.28 & 9.64 & 0.32 & 8.71 & 0.26 & 10.60 & 0.60 & 13.41 & 0.41 \\
\hline & EXT-EW or SW & 6.29 & 0.29 & 5.67 & 0.27 & 9.18 & 0.52 & 6.02 & 0.26 & 13.83 & 0.42 & 9.11 & 0.36 & 10.35 & 0.65 & 13.43 & 0.42 \\
\hline & INT-EW or SE & 14.72 & 0.46 & 9.00 & 0.39 & 13.19 & 0.53 & 9.11 & 0.38 & 9.02 & 0.33 & 9.32 & 0.35 & 11.50 & 0.84 & 13.79 & 0.43 \\
\hline Average & & \multicolumn{2}{|c|}{11.61} & \multicolumn{2}{|c|}{6.26} & \multicolumn{2}{|c|}{13.03} & \multicolumn{2}{|c|}{6.36} & \multicolumn{2}{|c|}{11.21} & \multicolumn{2}{|c|}{8.84} & \multicolumn{2}{|c|}{11.32} & \multicolumn{2}{|c|}{13.52} \\
\hline \multirow[t]{4}{*}{10 Levels } & EXT-NS or NW & 7.17 & 0.37 & 5.49 & 0.20 & 7.29 & 0.35 & 5.01 & 0.22 & 6.30 & 0.22 & 4.93 & 0.20 & 8.56 & 0.36 & 10.79 & 0.39 \\
\hline & INT-NS or NE & 7.76 & 0.33 & 5.46 & 0.20 & 7.66 & 0.33 & 5.02 & 0.23 & 12.82 & 0.47 & 4.62 & 0.18 & 6.90 & 0.38 & 10.66 & 0.39 \\
\hline & EXT-EW or SW & 8.48 & 0.37 & 5.74 & 0.24 & 6.84 & 0.31 & 5.31 & 0.26 & 10.99 & 0.36 & 5.13 & 0.19 & 7.68 & 0.37 & 10.67 & 0.37 \\
\hline & INT-EW or SE & 7.74 & 0.34 & 5.82 & 0.25 & 8.36 & 0.32 & 5.47 & 0.30 & 6.47 & 0.24 & 4.57 & 0.18 & 6.39 & 0.37 & 10.44 & 0.36 \\
\hline
\end{tabular}

MVs of $R_{\mathrm{L}}$ are lower than those of $R_{\mathrm{G}}$ in most cases. These results reflect, again, that the magnitude of $R$ significantly varies with the structural complexity and with the response parameter under consideration, contradicting the common practice adopted in the SELF procedure, where the global response parameter reduction is assumed to be the same as that of local response parameters. This similarity is not justified based on the results of this study. In addition, the same reduction value for low- and medium-rise buildings cannot be justified either.

In the International Building Code (IBC, 2009 edition), the $R$ parameter is called the response modification factor; it is stated that this factor mainly depends on the ductility capacity and on the inelastic performance of the structural material and system and that its maximum value (for special MRF) is 8 . In the National Building Code of Canada (2010 edition), as for the IBC code, the maximum specified $R$ value is 8 (most ductile buildings). It is inferred that the maximum $R$ value specified in Eurocode 8 (2004 edition) is about 8 . It is not clearly stated in these codes whether the effect of viscous damping should be considered. The values of the force reduction factor without considering the effect of viscous damping are given in Table $5\left(R_{\mu} R_{\Omega}\right)$. According to the results of this study for the more realistic $3 \mathrm{D}$ structural representation of steel buildings (SAC models) with PMRF, the value of 8 , specified in the codes for the $R$ parameter is justified only if viscous damping is considered (through the $R_{\zeta}$ factor) for the case of low-rise building models and global parameters (interstory shear), 
or for some particular cases of local response parameter ( $R_{\mathrm{G}}$, for example, ranges from 8.21 to 9.31 ). For mediumrise buildings, however, the value of 8 cannot be justified for both global and local response parameters $\left(R_{\mathrm{G}}\right.$, for example, ranges from 5.48 to 5.50$)$. If the effect of viscous damping is not considered (Table 5), the value of 8 cannot be justified in any case. The codes need to be more explicit concerning the components (and their magnitude) considered in the $R$ factor; a value of 6 is recommended.

\section{Conclusion}

The nonlinear seismic responses of steel buildings are numerically estimated and the force reduction factors $(R)$ are calculated; two levels of $R$, namely global $\left(R_{\mathrm{G}}\right)$ and local $\left(R_{\mathrm{L}}\right)$, are studied. The contributions of yielding, viscous damping and overstrength, through the ductility $\left(R_{\mu}\right)$, damping $\left(R_{\zeta}\right)$ and overstrength $\left(R_{\Omega}\right)$ reduction factors respectively, are discussed. $R_{\mathrm{G}}$ is estimated in terms of interstory shears, and $R_{\mathrm{L}}$ in terms of bending moments and axial loads. Two three-dimensional (3D) steel building models with 3 and 10 levels are used in the study. In addition, equivalent 3D (EQ) with only moment frames, two-dimensional, and equivalent SDOF structural representations, are considered.

The results of the numerical study indicate that the global $\left(R_{\mu \mathrm{G}}\right)$, or local $\left(R_{\mu \mathrm{L}}\right)$ ductility reduction factors; the global $\left(R_{\zeta \mathrm{G}}\right)$, or local $\left(R_{\zeta \mathrm{L}}\right)$, damping reduction factors, or the global force reduction factors $\left(R_{\mathrm{G}}\right)$, in general, may considerably vary from one building and from one structural representation to another, or from one type of response parameter and column location to another. This implies that the effect of the structural complexity and type of response parameter on the magnitude of these factors is considerable. It is also shown that the magnitude of $R_{\mu \mathrm{G}}$ and $R_{\zeta \mathrm{G}}$ (or $R_{\mu \mathrm{L}}$ and $R_{\zeta \mathrm{L}}$ ) can be very different, indicating that the effect of yielding on the reduction of seismic response should not be expressed in terms of elastic viscous damping. Results also indicate that $R_{\mathrm{G}}$ are greater for the 3-level than for the 10-level buildings, and that $R_{\mathrm{L}}$ for axial loads are much larger than $R_{\mathrm{G}}$, but $R_{\mathrm{L}}$ for bending moments may be much smaller than $R_{\mathrm{G}}$. This contradicts the common practice adopted in simplified analyses, where the reduction is assumed to be the same for global and local parameters as well as for low-, medium- or high-rise buildings. It is also shown that the dissipated energy and the force reduction factors are overestimated when the SD models are used, implying non-conservative designs. According to the results of this study for the more realistic (3D) structural representation of steel buildings with PMRF (SAC models), the value of 8 , specified in the codes for the $R$ parameter is justified only if viscous damping is considered for low-rise buildings and global parameters $\left(R_{\mathrm{G}}\right.$, for example, ranges from
8.21 to 9.3 ). For medium-rise buildings, however, the value of 8 cannot be justified for global or for local response parameters $\left(R_{\mathrm{G}}\right.$, for example, ranges from 5.08 to 5.50). If the effect of viscous damping is not considered, the value of 8 cannot be justified in any case; a value of 6 is recommended. Finally, it is highlighted that the codes need to be more explicit concerning the components of the $R$ factor.

1. Chopra, A. K., Dynamics of Structures, Prentice Hall, New Jersey, USA, 2007.

2. Reyes-Salazar, A., Ductility and ductility reduction factors for MDOF systems. Struct. Eng. Mech., 2002, 13(4), 369-385.

3. Uang, C. M., Establishing $R$ (or $R_{w}$ ) and $C_{d}$ factors for building seismic provisions. J. Struct. Eng., 1991, 117(1), 19-28.

4. Tso, W. K. and Naumoski, N., Period-dependent seismic force reduction factors for short-period structure. Can. J. Civ. Eng., 1991, 18, 568-574.

5. Whittaker, A., Hart, G. and Rojahn, C., Seismic response modification factors. J. Struct. Eng., 1999, 125(4), 438-444.

6. Rai, D. C., Future trends in earthquake-resistant design. Curr. Sci., 2000, 79(9), 1291-1300.

7. Kougioumtzoglou, I. A. and Spanos, P. D., An approximate approach for nonlinear system response determination under evolutionary stochastic excitation. Curr. Sci., 2009, 97(8), 12031211.

8. Sivaram, K., Gade, M., Raghukanth, S. T. G., Saikia, U. and Kanna, N., Estimation of strong ground motion in Southern Peninsular India by empirical Green's function method. Curr. Sci., 2017, 112(11), 2273-2283.

9. ATC, Tentative provisions for the development of seismic regulation buildings. Rep. No. ATC-3-06, Applied Technology Council, Redwood City, California, USA, 1978.

10. Newmark, N. M. and Hall, W. J., Earthquake Spectra and Design Monograph Series, Earthquake Engineering Research Institute, Berkeley, California, USA, 1982.

11. Hadjian, A. H., An evaluation of the ductility reduction factor Q in the 1976 regulations for the Federal District of Mexico. Earthq. Eng. Struct. D, 1989, 18, 217-231.

12. Miranda, E. and Bertero, V., Evaluation of strength reduction factors for earthquake-resistant design. Earthq. Spectra., 1994, (10)2, 357-379.

13. Ordaz, M. and Pérez-Rocha, L. E., Estimation of strengthreduction factors for elastoplastic systems: a new approach. Earthq. Eng. Struct. D, 1998, 27(9), 889-901.

14. Arroyo-Espinoza, D. and Teran-Gilmore, A., Strength reduction factors for ductile structures with passive energy dissipating devices. J. Earthq. Eng., 2003, 7(2), 297-325.

15. Karmakar, D. and Gupta, V. K., Estimation of strength reduction factors via normalized pseudo-acceleration response spectrum. Earthq. Eng. Struct. D, 2007, 36(6), 751-763.

16. Reyes-Salazar A. and Haldar A., Dissipation of energy in steel frames with PR connections. Struct. Eng. Mech., 2000, 9(3), 241256; doi:http://dx.doi.org/10.12989/sem.2000.9.3.241.

17. Reyes-Salazar, A. and Haldar, A., Energy dissipation at PR frames under seismic loading. J. Struct. Eng., 2001, 27(5), 588-593.

18. Reyes-Salazar, A. and Haldar, A., Seismic response and energy dissipation in partially restrained and fully restrained steel frames: an analytical study. Steel Compos. Struct., 2001, 1(4), 459-480.

19. Ramirez, O. A., Constantinou, M. C., Gomez, J. D., Whittaker, A. S., Kircher, C. A., Johnson, M. W. and Chrysostomoue, C. Z., Validation of the 2000 NEHRP provisions' equivalent lateral force and modal analysis procedures for buildings with damping systems. Earthq. Spectra, 2003, 19(4), 981-999. 
20. Medina, R. and Krawinkler, H., Strength demand issues relevant for the seismic design of moment-resisting frames. Earthq Spectra, 2005, 21(2), 415-439.

21. Ganjavi, B. and Hao, H., Effect of structural characteristics distribution of strength demand and ductility reduction factor of MDOF systems considering soil-structure interaction. Earthq. Eng. Eng. Vib., 2012, 11, 205-220.

22. Reyes-Salazar, A., Bojórquez, E., Velazquez-Dimas, J. I., LópezBarraza, A. and Rivera-Salas, J. L., Ductility and ductility reduction factors for steel buildings considering different structural representations. Bull. Earthq. Eng., 2015, 13(6), 1749-1771.

23. Reyes-Salazar, A., Llanes-Tizoc, M. D., Bojórquez, J., Bojórquez, E., Lopez-Barraza, A. and Haldar, A., Force reduction factors for steel buildings with welded and post-tensioned connections. Bull. Earthq. Eng., 2016, 14(10), 2827-2858.

24. Carr, A., RUAUMOKO-inelastic dynamic analysis program, Department of Civil Engineering, University of Cantenbury, New Zealand, 2011.

25. Chen, W. F. and Atsuta, T., Interaction equations for biaxially loaded sections. Fritz Laboratory Report (72-9), Lehigh University, Pennsylvania, USA, 1971.
26. FEMA, State of the art report on systems performance of steel moment frames subjected to earthquake ground shaking, SAC Steel Project, Report 355C, Federal Emergency Management Agency, USA, 2000.

27. Assaf, A. F., Evaluation of structural over strength in steel buildings systems. Master's thesis, Northeastern University, Boston, Massachusetts, USA, 1989.

28. Uang, C. M. and Bruneau, M., State-of-the-art review on seismic design of steel structures. J. Struct. Eng., 2018, 144(4), doi:10.1061/(ASCE)ST.1943-541X.0001973.

ACKNOWLEDGEMENTS. This research received financial support from Universidad Autónoma de Sinaloa, México under grant PROFAPI $2015 / 235$. The conclusions made in this publication are those of the authors and do not reflect the opinions of the sponsors.

Received 4 January 2018; revised accepted 26 February 2019

doi: $10.18520 / \mathrm{cs} / \mathrm{v} 116 / \mathrm{i} 11 / 1850-1860$ 